\title{
LOS DESTINOS DE DON QUIJOTE EN CHECOSLOVAQUIA
}

La primera traducción al checo de la inmortal obra de Miguel de Cervantes, Don Quijote, aunque incompleta, apareció hace un siglo y cuarto. El año 1864 la publicó el editor Josef Pečírka como "Lectura de pasatiempo" popular. La traducción completa de esta novela kuniversal pero al mismo tiempo esencialmente española" ${ }^{1}$ fue realizado por primera vez por J. B. Pichl en el año 1866 (tomo I) y $\mathrm{K}$. Stefan (tomo II) dos años más tarde. Desde aquellas fechas han aparecido varias traducciones más, algunas de ellas en varias ediciones, versiones y adaptaciones ${ }^{2}$. Sin embargo, otros trabajos de Cervantes penetraron en la lectura popular por una traducción que data ya del año 1838. Esto significa que desde los inicios de la literatura moderna checa, este escritor castellano ha sido una gran figura de la literatura universal para el lector checo, en cuyo subconsciente se queda desde hace ya un siglo y medio (al lector español hay que recordarle que la continuidad de la literatura checa sufrió una gran crisis de identidad a causa de la germanización oficial por parte del imperio austríaco y debido a los alemanes que vivían en el territorio de la actual Checoslovaquia, antes Reino de Bohemia). Uno de los principios fundamentales estético-artísticos y poéticos fue el кanhelo de la plena vivencia, el papel del individuo, de la libertad y la verdad", tal como se muestran de forma magistral

1 J. Chuвis, Déjiny šanělské literatury (Historia de la literatura española, edición checa). Praga, 1960, p. 176.

2 J. ChabÁs, op. cit. (nota 1). Su lista la preparó O. Bělič. 
en Cervantes ${ }^{3}$. Por boca de su inmortal héroe expresa Cervantes unas ideas que se convertirian en fundamentales para el romanticismo, pasando como un legado al pensamiento moderno y convirtiéndose en ideales eternos de la libertad.

Sin embargo, este encuentro del ambiente checo con Cervantes no fue ni de lejos el primero. El original de Don Quijote penetró en esta tierra mucho antes, prácticamente desde la salida del libro. La primera información escrita que se ha conservado testimonia que en junio de 1620 llega un ejemplar de Don Quijote a manos de un lector que lo leyó seguramente, pues este destinatario, el cardenal de Dietrichstein, obispo de Olomouc, educado en España, sabía castellano perfectamente. El mismo año se le llamó al rey protestante checo, el «Rey del Invierno», Federico del palatinado, "Don Quijotew, lo cual supone una cierta consciencia de este personaje literario dentro del Reino de Bohemia poco después de la primera edición del libro en España 4 .

No obstante, las recientes investigaciones españolas en las bibliotecas checoslovacas principales s, revelan que se encuentra en ellas más de un ejemplar de las primeras ediciones de Don Quijote; por ejemplo, la valenciana, que apareció después de la madrileña pero aún en el mismo año, es decir 1605. Sin embargo, la primera edición madrileña la encontramos en la antigua biblioteca de Lobkowicz (Lobkovice) de Roudnice, hoy en la Biblioteca Universitaria (Nacional) de Praga. Y no es casualidad sino una consecuencia, como ahora veremos, pues si observamos la colección de retratos expuesta hoy en la colección de arte antiguo

${ }^{3}$ J. Hanzal, Od baroka Kromatismu. Ke zrozeni novodobé české Kultury (Del barroco al romanticismo. Hacia el nacimiento de la cultura moderna checa). Praga 1987, p. 199. En otro lugar (p. 78) Hanzal recuerda que la literatura checa de la Ilustración estaba muy relacionada con los libros de lectura popular y con las novelas caballerescas, que seguian siendo preferidas por un público popular, el cual continuaba con los modelos tradicionales y medievales. Podemos deducir de ello que precisamente por esa lectura el público está preparado para aceptar a Don Quijote.

4 J. PoliśrenskY-J; Hrubeš, «Cervantes a Cechy (Cervantes y Bohemia)», Déjiny a soucasnost, Praga, 1966, n. 10, pp. 14 y 15.

${ }_{5}$ Soupis Starych tiskú ve fondech státni vèdecké Knihovny v Olomouci. $I V$. Hispanika a iberoamerikána (1501-1800) (Registro de Impresos en los fondos de la Biblioteca Científica de Estado en Olomouc. Materiales hispánicos e hispanoamericanos) (El registro fue preparado por V. PUMPRLA en colaboración con 0. KAŚPAR). Olomouc 1981. O. KAŚPAR, "Cervantes y Olomouci» (Cervantes en Olomouc), Zprávy Krajského vlastivědného muzea v Olomouci (Olomouc), 1983, n. 222, pp. 28-30; 0. KAŠPaR, Soupis Spanělskych tiskú bivale Knihovny v Roud nici nad Labem, nyni deponovanyach ve státni knihovnè CSk v Praze. (Registro de impresos españoles de la antigua biblioteca del Palacio de Roudnice nad Labem, depositados actualmente en la Biblioteca de Estado de la RSCh en Praga). Praga 1983. 
de la Galería de Bohemia Central (Středočeská galerie) en el palacio de Nelahozeves, encontramos ahí la imagen de una doncella vestida de negro, a la edad de siete u ocho años. Se trata de María Luisa de Villahermosa, hija de Fernando de Aragón, quinto duque de Villahermosa, y de Juana de Pernestán (Pernstejn, Pernstein), a su vez hija del canciller del Reino de Bohemia Wratislao de Pernestán y María Manrique de Lara y Mendoza, matrimonio que inicia desde 1555 una corriente hispánica y de hispanización de la nobleza checa. El lienzo que representa a María Luisa fue pintado por Juan Pantoja de la Cruz en Madrid, y fechado en 1593. La muchacha lleva en la mano derecha una carta que dice textualmente: «A la ilustrísima y excelentísima doña María Manrique mi aguela, etc., a Pragan, o sea, se indica que el cuadro fue destinado a la abuela de la portadora de la carta ${ }^{\circ}$.

María Luisa es un personaje interesante también por otras razones; si nos sumergimos en la lectura del segundo tomo de Don Quijote, encontramos, casi al final, 28 capítulos (XXX al LVIII) que relatan la estancia del caballero y de su escudero en la mansión de una pareja ducal. El duque y la duquesa han sabido distinguir la alteza trágica del heroísmo moral que dominaba a Don Quijote así como la profundidad un poco ingenua, pero honrada sinceridad y la castiza buena voluntad que identifica la personalidad de Sancho Panza. Dicha pareja ducal tuvo un modelo real, de la misma manera que tampoco fueron inventados los molinos de viento que en la fantasía de Don Quijote se convirtieron en gigantes enemigos. Según la tradición recogida ya en el siglo XVIII por Juan Antonio Pellicer 7 , el duque que sirvió como modelo del anfitrión fue Carlos de Borja,y su mujer no es otra que la retratada por Pantoja, María Luisa. Profundicemos: el padre de Carlos, Juan de Borja, fue embajador de España ante la corte imperial de Praga en los años 1578 a 81 8; el mismo emperador

6 P. Stépanek y E. Bukolska, «Retratos españoles de la colección Lobkowicz en Roudnicen, Archivo Español de Arte, XLVI, 1973, n.॰ 183, pp. 319-339; E. BukOLSKA-P. STépÁneK, Spanélské podobizny (Retratos españoles). Praga 1980, n.⿻ 13 y 14.

7 Según V. CERNY, «Ceská groteska donquijotská» (El grotesco checo donquijotesco), Lidová demokracie. Praga, 17-IV-1966.

8 Juan de Borja publicó sus famosos Emblemas Morales en Praga en 1581 en español. Su importancia quedó subrayada por su reciente reedición española: Juan de Borja, Empresas Morales. Edición e introducción de Carmen BravoVillasante. Véase también P. Vóit, Minulost prǎsského Knihtisku (El pasado de la impresión de libro en Praga). Catálogo de la exposición celebrada en diciembre de 1987 a enero de 1988 en la Biblioteca de Estado de la RSCh, reprod. n.• 37, núm. del inv. SK CSR. Sobre María Luisa véase Spanelské umeni 14-16. stoleti $z$ ts. sbirek (Arte español de los siglos XIV al XVI de las colecciones checostovacas). Praga XII-1984 - II-1985, núm. del cat. 16. Catálogo de P. STẺPÁNEK 
Rodolfo II fue educado en su juventud en España, y Juan de Borja es, a su vez, hijo de Francisco de Borja, el Gran Duque de Gandía, conocido más como San Francisco de Borja. En honor a éste, después de convertirse en general de los jesuítas y llegar a ser conocido como santo, se le yergue, en 1710, una gran estatua de piedra en el puente Carlos, en la ruta más frecuentada de la capital del reino de Bohemia, obra del segundo escultor checo más importante, Fernando Maximiliano Brokof, convertido a su vez del luteranismo al catolicismo. Y para culminar esta cadena de "casualidades», se encuentra un manuscrito original, atribuido nada menos que a Pedro Calderón de la Barca, en el palacio checo de Mladá Vožice?.

Con lo arriba descrito hemos dado un pequeño rodeo, aunque no sin lógica. Se ofrece una breve conclusión: como los duques de Villahermosa residían y siguen residiendo en el palacio de $\mathrm{Pe}$ drola, cerca de Zaragoza, era allí donde pudieron haber sido hospedados Don Quijote y Sancho Panza, si no era en el palacio madrileño, actualmente parte del Museo del Prado ${ }^{10}$. Sea cual fuere la realidad, entendemos que hubo más de un motivo para que la primera edición de Don Quijote se encuentre en la antigua biblioteca de los Lobkovice, en Roudnice.

Pero con ello no se dan por terminadas las relaciones históricas quijotescas en el Reino de Bohemia: vamos a ver un testimonio especial sobre la lectura de Don Quijote en Bohemia en el siglo XVIII. Indudablemente fue una lectura apasionada, porque sabemos su resultado: el año de 1725 la condesa Anna Paar mandó construir en el pueblo de Budišov, cerca de Trebic, su propiedad, una torre -en la iglesia local- en forma inspirada por la lectura de Don Quijote, dicho de otra manera, extrajo e imaginó la forma de la torre de la lectura de la novela cervan-

9 María Josefa Harrach, hija de Fernando Bonaventura Harrach (1637-1706), entonces embajador imperial en Madrid (enviado por Leopoldo I). A su regreso a Bohemia casó con el conde Juan José Kuenburg y los manuscritos y libros españoles pasaron a la sede de los Kuenburg en Mladá Vožice. El retrato de María Josefa de un pintor madrileño, probablemente Ruiz de la Iglesia, se encuentra en el palacio de Hrádek u Nechanic junto con otros retratos de sus hermanos, pintados asimismo en Madrid. En la citada biblioteca también encontramos una edición de Don Quijote del año 1647 que habrá adquirido la propia condesa de Harrach; véase J. Polišsenský-J. Hrubeś, op. cit., nota 4, p. 15. Entre los manuscritos destacan dos, publicados por V. Cerný: El Gran Duque de Gandía Comedia de Don Pedro Calderón de la Barca. Praga, 1963. Introducción, notas y vocabulario por V. Cerný. El segundo manuscrito, No hay que crer ni en la verdad fue publicado en Madrid en 1968. Edición y estudio de V. Cerný.

10 V. CERNY, op. cit., nota 7, ibid. 
tina ". Este caso, único en Europa, muestra mejor que nada hasta qué profundidad enraizó la lectura del caballero andante en el ambiente de Bohemia ${ }^{12}$.

Podemos suponer además que, aparte del original español, Don Quijote fue leído también en otras lenguas, sobre todo italiano y francés, además ilustrados -a veces profusamente-, como lo testimonian los ejemplares conservados en bibliotecas palaciegas $o$ colecciones museísticas (en caso de haberse recortado los grabados). $\mathrm{Y}$ aquellos que no dominaban las lenguas latinas, podían aprovechar ediciones alemanas, sobre todo en el período del romanticismo, en el siglo XIX.

Así es que se plantea una cuestión que nos interesa en este caso con especial importancia: ¿cuándo aparece por primera vez una representación plástica del héroe cervantino en el arte checo? En tanto que ilustración, es con Karel Purkyně y Quido Mánes, quienes ilustran la primera edición completa checa del año 186668. En cuanto a pintura, los ilustradores tienen un antecedente importante en Eduard Svodoba (1814-1902) que representó a Don Quijote en compañía de Sancho Panza y Dulcinea dentro de una serie de destacadas personalidades literarias, pintadas en 1849 para los dueños del palacio de Rájec nad Svitavou, los Salm (a propósito de esta familia, también tiene ramificaciones en España, pues uno de los Salm y Salm está enterrado en Pastrana). El óleo de Svodoba abre una larga serie de Don Quijotes en las artes plásticas checas que se va ampliando desde entonces y que en la obra de algunos pintores hasta alcanza decenas o incluso centenares de realizaciones de todo tipo, como ocurre con Karel Soucek (1915-1982). O decenas de ilustraciones que, sin embargo, no son motivadas por un encargo de ilustrar el libro, sino por una relación más profunda de los artistas checos hacia este héroe literario, hasta el de identificarse con su heroica lucha por los ideales. Logró Cervantes plasmar la figura tragicómica de este

1 B. LIFKA, Knihovny státních hradú a zámkú (Bibliotecas de los castillos y palacios estatales). Praga, 1954, p. 2.

12 En la misma época surgieron cartones para los gobelinos con el tema de Don Quijote, realizados en la Manufactura estatal francesa, según los cartones de Charles Coypel (1694-1752), aunque a su actual sitio -el palacio de Konopište - llegaron más tarde y sólo una parte quedó ahí. Recordemos en esta oportunidad al Pintor Jean Baptiste Brelin de Fontenay (1653-1715) "como prisionero que expresó plásticamente su idea del caballero de la triste figura, y de él habrá salido la idea de aplicar los motivos de la novela a la decoración de los salones (en Konopiste) en los anos de 1715-1738x, aunque algunos gobelinos no fueron realizados hasta en el año 1774. Véase J. PoLAK, «Konopistské gobelinys historii o Donu Quijotovi» (Los gobelinos de Konopiste con la historia de Don Quijote), Uméni (Praga), VIII, 1934, pp. 17-27. 
caballero tan sugestivamente, que sus palabras se convirtieron casi en una receta obligada para muchos ilustradores ${ }^{13}$. No es casualidad el que haya escogido un tipo alargado, flaco y entrado en años, con rasgos de asceta e idealista, a quien se le ha usecadox el cerebro por la mucha lectura. Es que estas cualidades corresponden a la entonces difundida teoría de la patología humoral que destacaba desproporciones cualitativas como causa de la enfermedad ${ }^{14}$. No hay por qué extrañarse. En el subconsciente sigue manteniéndose upor siglos, exanimada interrelación de las disposiciones a autosacrificarse con el tipo asténico" ${ }^{15}$. El tipo plásticamente inmutable de los dos héroes principales de Don Quijote y Sancho Panza lo había fijado ya Gustavo Doré, aunque el tipo del alto asténico y huesudo caballero y el pequeño y rechoncho escudero cristalizan ya en ilustraciones del francés-alemán Tony Johannot en 1836-18 ${ }^{16}$. Y ya no profundizaremos en los antecedentes ya mencionados: ilustraciones de libros antiguos y demás gobelinos ${ }^{17}$, que desde la primera edición ${ }^{18}$ ilustrada del año 1622 hubo muchas más. sólo recordaré que en la pintura europea del siglo XVII surgieron algunos cuadros que eternizan al héroe cervantino ${ }^{19}$.

A pesar de que el héroe está definido de una vez para siempre y de que los artistas respetan la descripción del escritor, no llegan a repetirse hasta el cansancio las situaciones típicas en las que se encuentra Don Quijote, mostrando una sorprendente variedad.

Dejo para el final un comentario sobre las representaciones más importantes de Don Quijote en las artes plásticas checas,

${ }^{13}$ Las ilustraciones de las traducciones checas fueron expuestas en la pequeña exposición de Don Quijote en la ilustración preparada por el autor de este artículo para el Museo Nacional de Literatura (Památník národniho pisemnictvi) de Praga, del 17-VIII al 31-LX-1986.

14 R. Dostá, Pavel Simon, Drobna grafika (P. Simon. Grabado pequeño). Edice Obolos, Praga, 1971, p. 8.

15 E. Auerbach, Mimesis. Praga, 1968, p. 10 (edición checa). P. 310. Sobre la teoría humoral véase P. STÉPANEK, Lekarstvi ve výtvarném galerie (Galeria de Bohemia Central), noviembre 1987-enero 1988 , sin página.

${ }^{16}$ Como una interrelación estadísticamente comprobable lo demostró Kretschmer; véase S. SABOUK, Jazyk uméni (El lenguaje del arte). Praga, 1969, p. 44.

17 B. K Tony Johannot, Meister der Buchkunst. Berlín, 1956; J. HofmeisTERovA, «Cervantesúv Don Quijote ve svétové ilustraci» (Don Quijote de Cervantes en la ilustración mundial), Výtvarné uméni, Praga, 1955, n.॰ 9, p. 427.

$18 \mathrm{~J}$. GIJ, «El primer gravat de Don Quixot i Sancho és d'un artista francés", Revista de llibreria antiquària, Barcelona, 1986, n.` 11, pp. 36-37.

${ }^{19}$ Por ejemplo Dominicus van Wynen, Ascanius (Amsterdam, 1661-1690), «Don Quijote en una posada*, óleo sobre tela, $73 \times 73$, Budapest, Museo de Bellas Artes, núm. del inv. 221. 
que se desarrollan en torno a los siguientes nombres: Quido Mánes y Karel Purkyne (1828-1880 y 1834-1868, respectivamente), Vratislav H. Brunner (1886-1928), Frantisek Tichy (1896-1961), Cyprián Majernik (1909-1945), Karel Soucek (1915-1982), a los que se agregan decenas de nombres más. Dichos artistas crearon el mayor número de interpretaciones libres y muy personales en las que actualizan a Don Quijote de acuerdo con principios y situaciones eternamente válidos. En la exposición que fue pretexto para escribir este texto ${ }^{20}$ y que se limitó a artistas ya clásicos (esperando poder llevar a cabo otra que recogiera la numerosa obra de los contemporáneos), aparece, sobre todo, el conjunto de obras de Karel Soucek, que es precisamente el prototipo de artista que nos importa. Su obsesión y coincidencia con el objeto de su creación según el modelo literario no está causada por un impulso externo, por ejemplo por un encargo de ilustraciones, sino por un impulso interno que es la identificación con el héroe sin miedo y sin tacha. Una identificación con el luchador por ideales, en el cual muchos artistas se convierten sin reparar en los sacrificios que han de sufrir para llegar a un (su) ideal. La identificación de los artistas con la figura de Don Quijote no es casual ni tampoco reconstrucción ideal especulativa y retroactiva del espectador o teórico con distancia de tiempo. Lo testimonia, entre otras cosas, un dibujo de Cyprián Majerník en el que Don Quijote lleva el escudo con un monograma CM, o sea, las iniciales de su propio nombre. Difícil ofrecer una prueba mayor de identificación del artista con su héroe, con su tema ${ }^{21}$.

En el primer ciclo más extenso de ilustraciones, dibujó Quido Mánes los modelos para las xilografías bajo la influencia de Daumier (aquí tenemos que distinguir entre los dibujos extraordinariamente libres y sueltos y su realización por el grabador) y con el eco de la obra de su hermano Josef, fundador del arte moderno checo. Cada imagen está concebida como una inicial para cada respectivo capítulo de la traducción checa del primer tomo (hay 52). Cierta austeridad de representación se convierte en un estilo, y la realización xilográfica unifica sus dibujos con los de Karel Pukyne ${ }^{22}$. Los trabajos de los dos ilustradores se identifican bastante bien, a pesar de la diferencia del carácter artístico ${ }^{23}$.

En el caso de Ferdinand Engelmueller (1867-1924), su Don Quijote y la segunda variante, llamada Fuego fatuo (Bludicky), están

${ }^{20}$ Pavel Simon dice según R. Dostál, op. cit., nota 14, p. 19: «En cada uno de nosotros hay algo de Don Quijote, queramos o non.

${ }^{21}$ Quido Manés, Don Quijote. Praga, 1923. Introducción de J. Rambousek.

22 J. HOFMEISTEROVA, op. cit. nota 17, p. 427.

${ }^{23}$ L. HLAVÁČEK, «Ferdinand Engelmuellem, Umeni, XXXV, 1985, pp. 425-447. 
concebidos dentro del espíritu del simbolismo de su época, donde el cielo y la tierra expresan tensión y contraste.

Poco después crea Vratislav H. Brunner una serie de dibujos llenos, por el contrario, de agitación y drama, cuando experimenta unas vivencias a lo Daumier, con el cual le unían posturas humanas así como la admiración romántica por Don Quijote. La influencia del gran maestro francés se mostraría más de una vez en los artistas checos. Sin embargo, hay que decir que Brunner no ilustró el Don Quijote de Cervantes, sino el del poeta checo Viktor Dyk (1877-1931) quien interpreta al personaje cervantino en su pieza teatral Entrada en razón de Don Quijote ${ }^{24}$. El hidalgo español interesó tanto por su carácter al pintor Brunner, que llegó a crear centenares de dibujos con las más diversas expresiones, de los cuales escogió sólo cinco ilustraciones para dicho libro de Dyk, pero publicando otras más independientemente del texto ${ }^{25}$. Brunner sucumbió por completo a los encantos de las figuras y del donquijotismo, que le tocaron en lo más hondo de su corazón, estilizando su propia persona en sus situaciones y en la filosofía vital ${ }^{26}$.

Diez años más tarde Vlastimil Rada (1895-1962) entiende a los dos héroes - Don Quijote y Sancho Panza- como peregrinos de la vida.

El tema de Don Quijote se reanima, y no sólo en las artes plásticas checoslovacas, durante los años treinta; y ello indudablemente en relación con los acontecimientos españoles que culminan en la Guerra civil, acontecimientos que vuelven la atención del mundo entero hacia la Península Ibérica, su realidad e historia ${ }^{27}$. Desde 1937 repite Cyprián Majerník muchas veces el mo-

${ }^{24}$ V. H. Brunner, Quijoti. Praga, 1931. Acompañado con notas Method Kaláb z B. M. Klika.

25 O. PechovA, V. H. Brunner, Výrtvarná Kultura. Praga, 1986, n.॰ 5, p. 31.

26 Un precursor parece ser GUSTAV WINTER, Don Quijote na rozcesti (Don Quijote en una encrucijada). Praga, 1935, p. 9, quien recuerda los versos de Machado: "veréis llanuras bélicas y páramos de asceta/-no fue por estos campos el bíblico jardín-/son tierras para el águila, un trozo de planeta/por donde cruza errante la sombra de Caín*, como una premonición de la Guerra civil española. A su vez J. SvesTKA, „Don Quijote und die spanische Tradition», in: Für Spanien. Internationale kunst und Kulkur zum Spanichen Bürgenkrieg. Museum Bochum, 28-IX - 23-XI-1986, sin pág., señala que los luchadores por la República española eran de cuño donquijotesco. Se conoce bien en Checoslovaquia el poema de Frantiśex Halas, Don Quijote en la barricado.

27 KAREL SoučER, Obrazy, Kresby, ilustrace (Cuadros, dibujos, ilustraciones). Stłedoceská galerie, Praga, de octubre a noviembre de 1980. Introducción B. Jirácková. 
tivo de Don Quijote, culminando su esfuerzo quizás en la litografía. Aprovecha fuertes contornos de dibujo al que dota de un despegue y frescura, de un toque inmediato y directo, que pierde en su pintura al óleo. Pero, por otro lado, la materialidad de la pintura así como la omisión de detalles logra un sabor térreo y de monumentalidad, multiplicada por el hecho de que capta al caballero andante en un momento de tranquilidad, en un momento de posarse y pararse, cuando observa el horizonte, mientras que en la litografía aparece aún (o ya) en movimiento, aunque esta observación no es válida para todos los casos.

Una personalidad prominente de la vanguardia checa de los años cuarenta, František Tichý, resuelve con inaudita fantasía los problemas de la ilustración de Don Quijote en una edición abreviada y adaptada por Jaromir John ${ }^{28}$, destinada ante todo a la juventud. Esta adaptación apareció en varias ediciones y contribuyó así a la enorme popularidad del hidalgo cervantino entre lectores jóvenes. Tichý es uno de los pocos que presta atención, no solamente a Don Quijote, sino también representando aisladamente a Sancho Panza e incluso al caballo Rocinante.

Karel Soucek trabaja paralelamente con Tichý, pero su obra llega a ser conocida más tarde, pues prácticamente inicia su trabajo en 1936 y lo continua hasta su muerte en 1982, en pinturas e ilustraciones que no llegan a publicarse. En sus últimos lienzos no sólo evoca la atmósfera del modelo literario o incluso del paisaje español que antes de finalizar su vida llega a conocer, sino que lo actualiza para expresar su repudio y crítica de la sociedad de consumo.

Don Quijote es realmente un símbolo de humanismo en su lucha sin cuartel, de antemano perdida, contra la preponderancia, así como en su esfuerzo por ayudar a los afectados o débiles, fiel a su ideal. En levantarse, tras ser apaleados y ofendidos los Quijotes, para seguir lo absurdo de sus sueños, está representada una buena muestra del género humano ${ }^{29}$. Seguido con admira-

28 J. Ciganek, «Don Quijote nás soucasník» (Don Quijote nuestro contemporáneo), Divadlo. Praga, noviembre de 1966, p. 73.

${ }^{29}$ La literatura sobre Don Quijote y sus ilustraciones es tan extensa que seria posible escribir un estudio dedicado exclusivamente a esta literatura. Existe incluso una tesina defendida en la Universidad Carolina: S. KozAkovA, Ilustraciones de Don Quijote, Praga, 1969, la cual, sin embargo, no he tenido la oportunidad de estudiar. Pero recordemos que el nombre de Don Quijote es utilizado incluso para denominar todo un siglo que le tocó vivir; por ejemplo, en la serie fundada por R. Menéndez Pidal y dirigida por J. M. JOVER ZAMORA, El siglo de Don Quijote (1580-1680), I. Religión, Filosofia, Ciencia. Madrid, 1986. 
ción por los artistas y los lectores, a pesar de todas las caídas, palizas y burlas, siguen recorriendo el caballero andante y su escudero la calle de los siglos ${ }^{30}$.

PAVEl StêPánek

${ }^{30}$ Este texto ha sido elaborado con motivo de la exposición de Don Quijote en el arte checo, que preparé para la Galería de artes plásticas de la ciudad de Kladno y que reunió 84 obras propiedad de las galerías estatales de todo el país, excepto la Nacional, cuyo director, Jiłi Kotalik, se negó a prestar cualquier obra. 


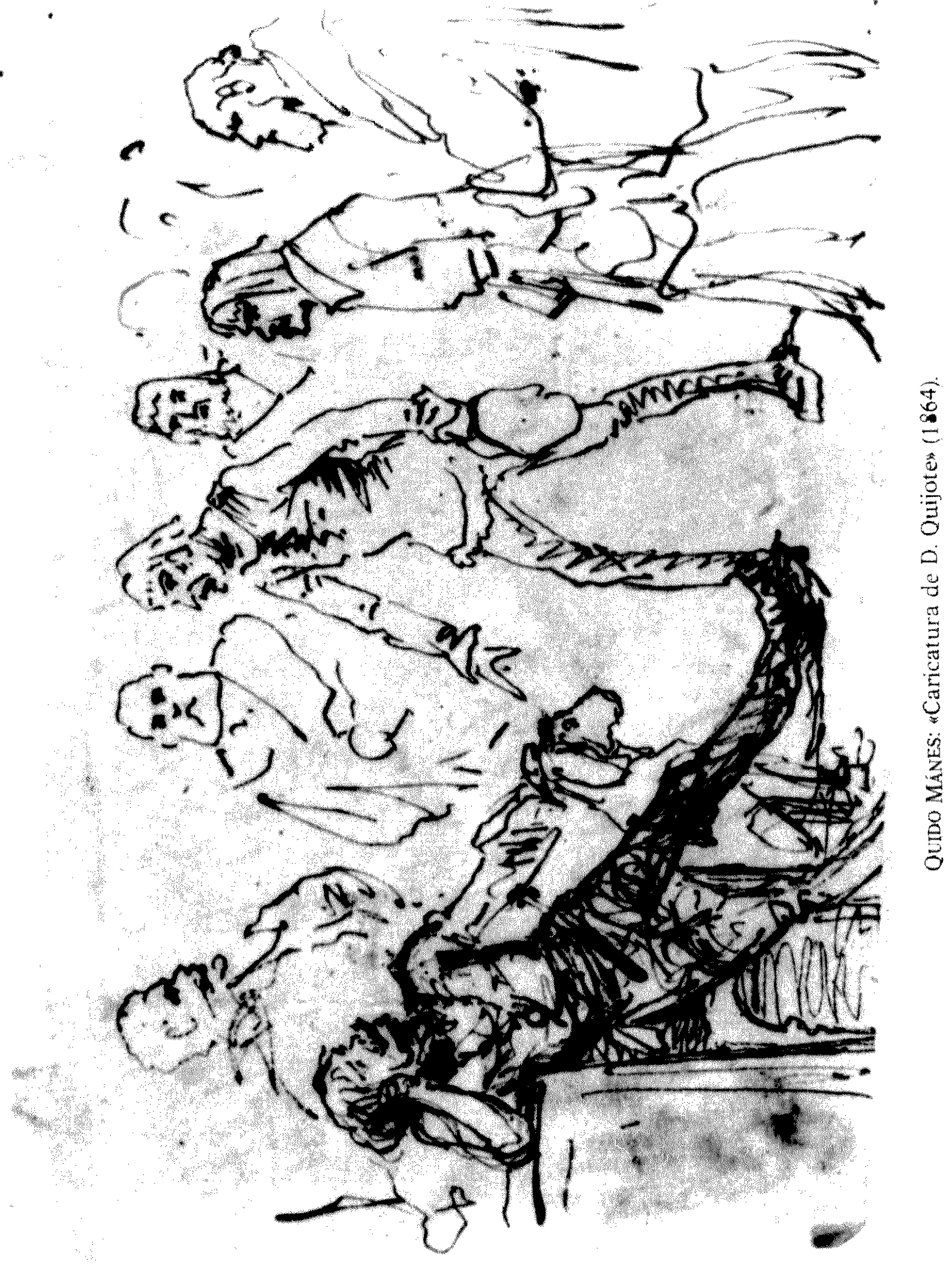




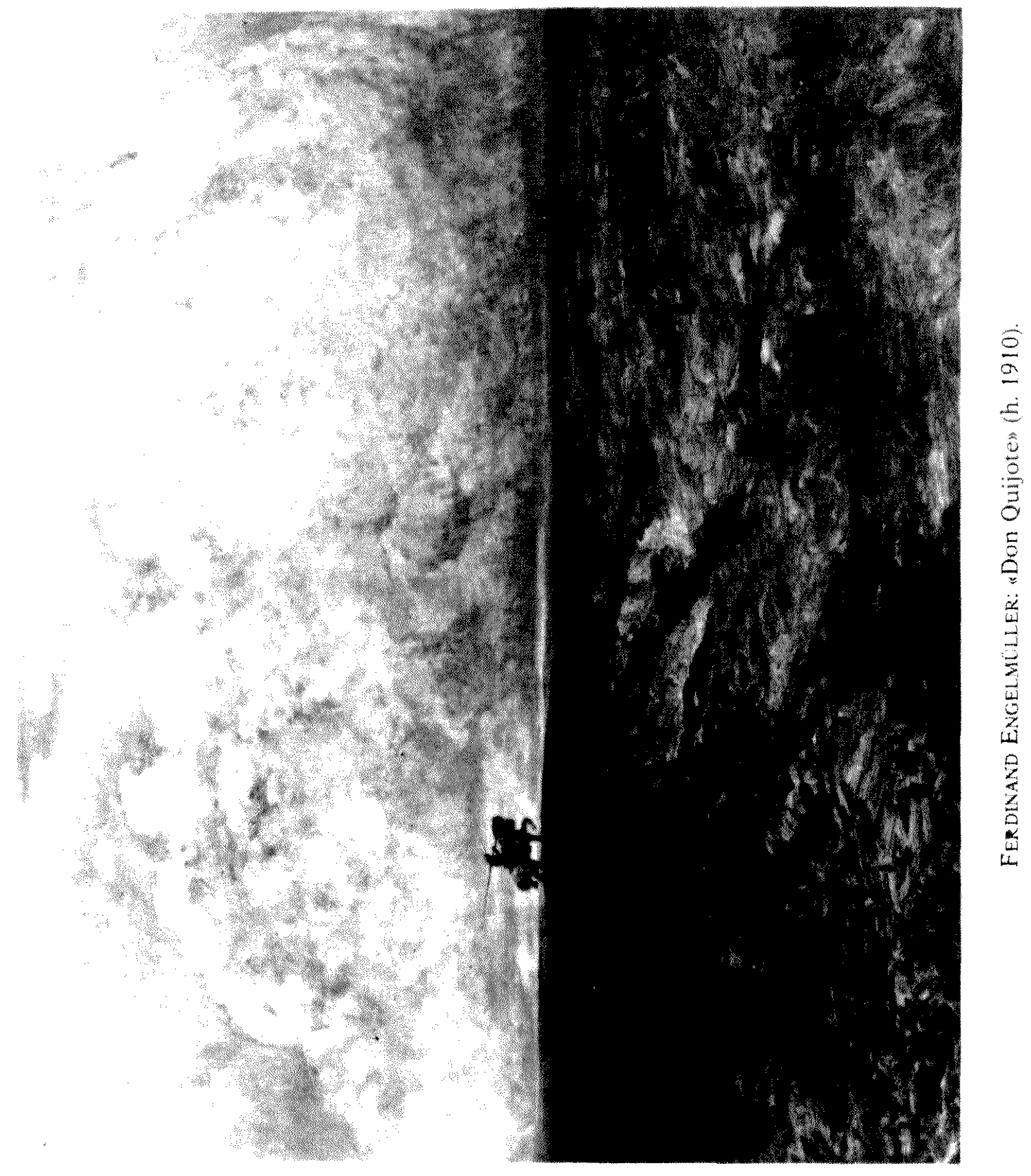




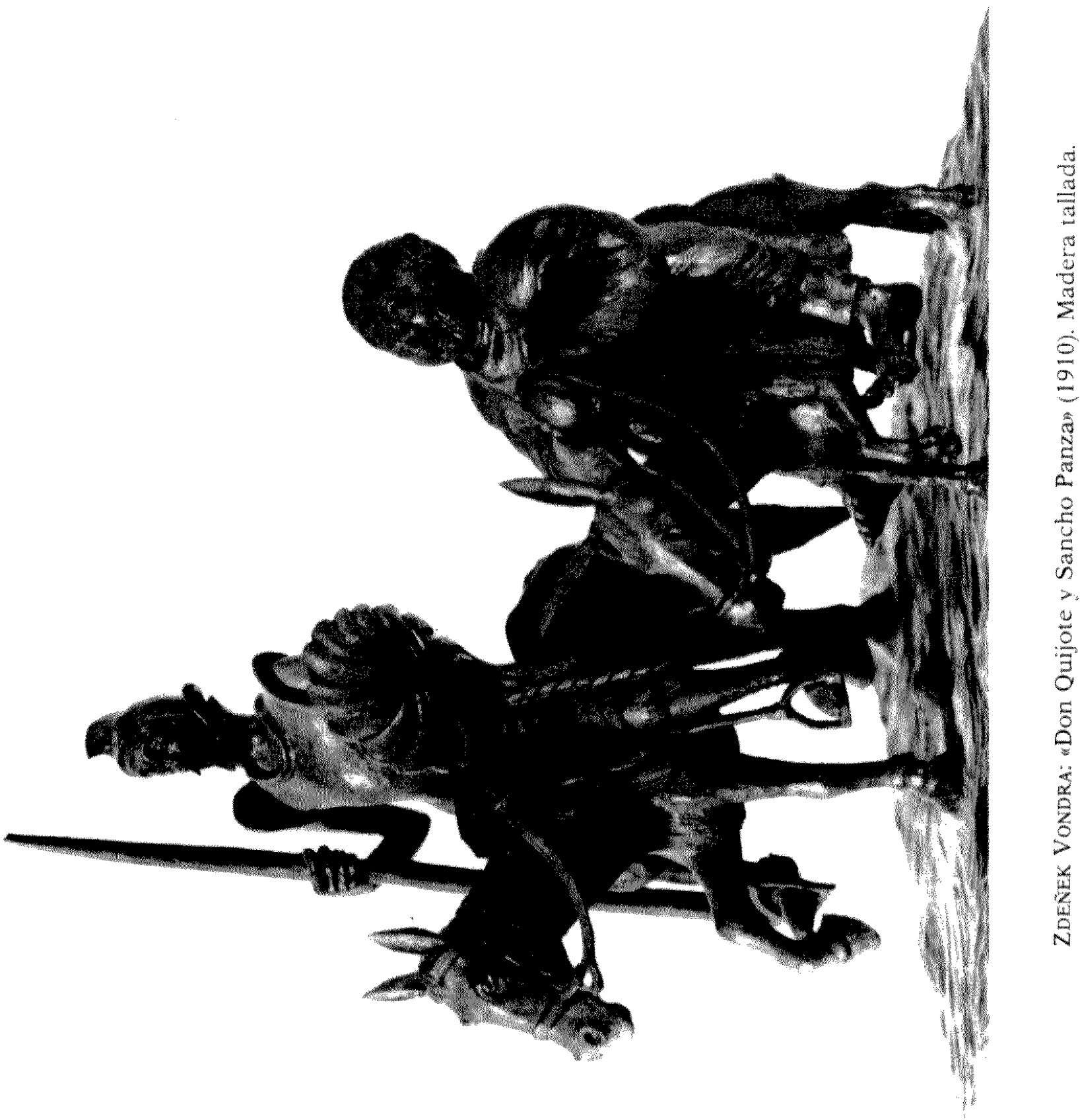




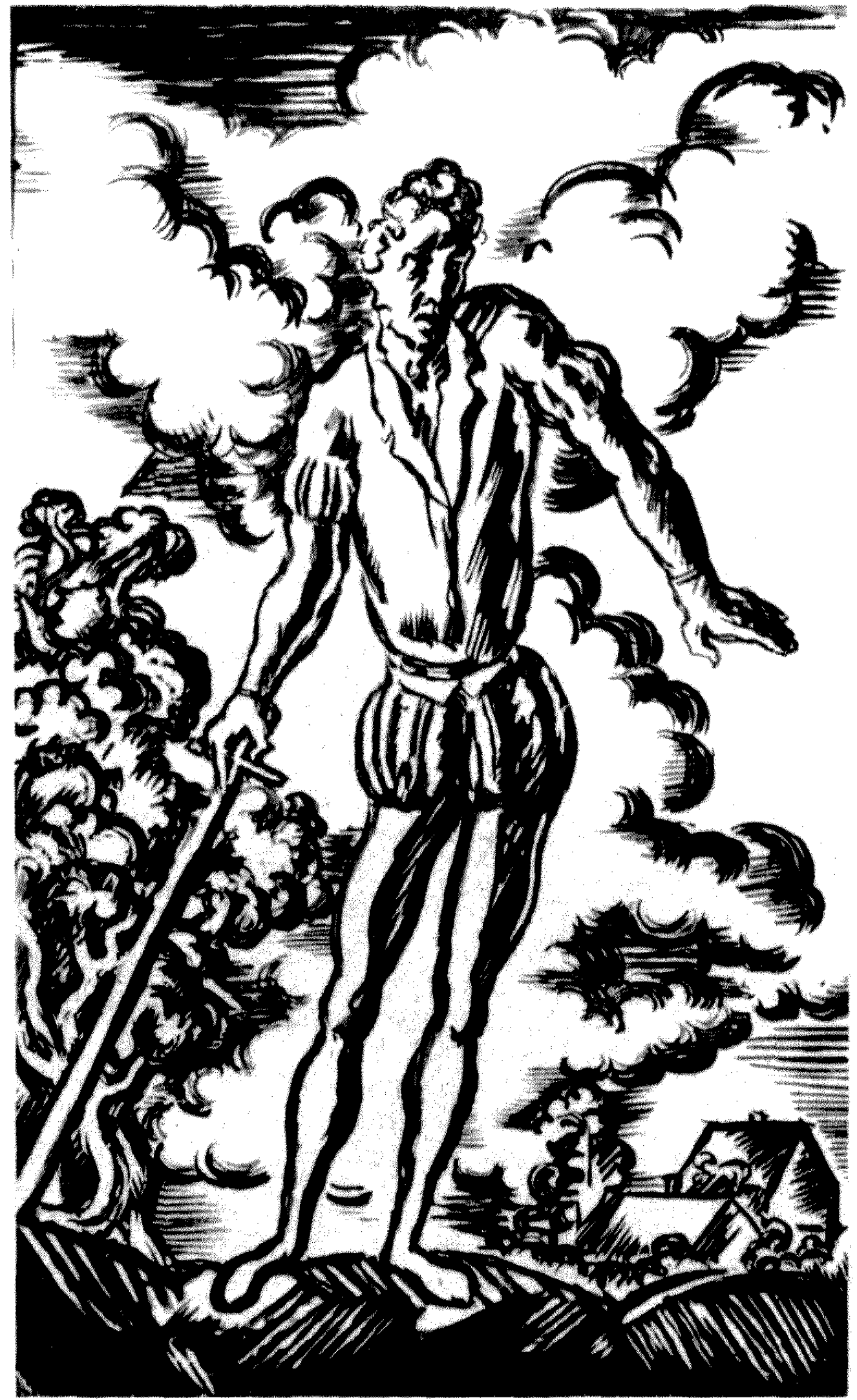

Vratislav H. Brunner: "Won Quijote" (hacia 1913). 


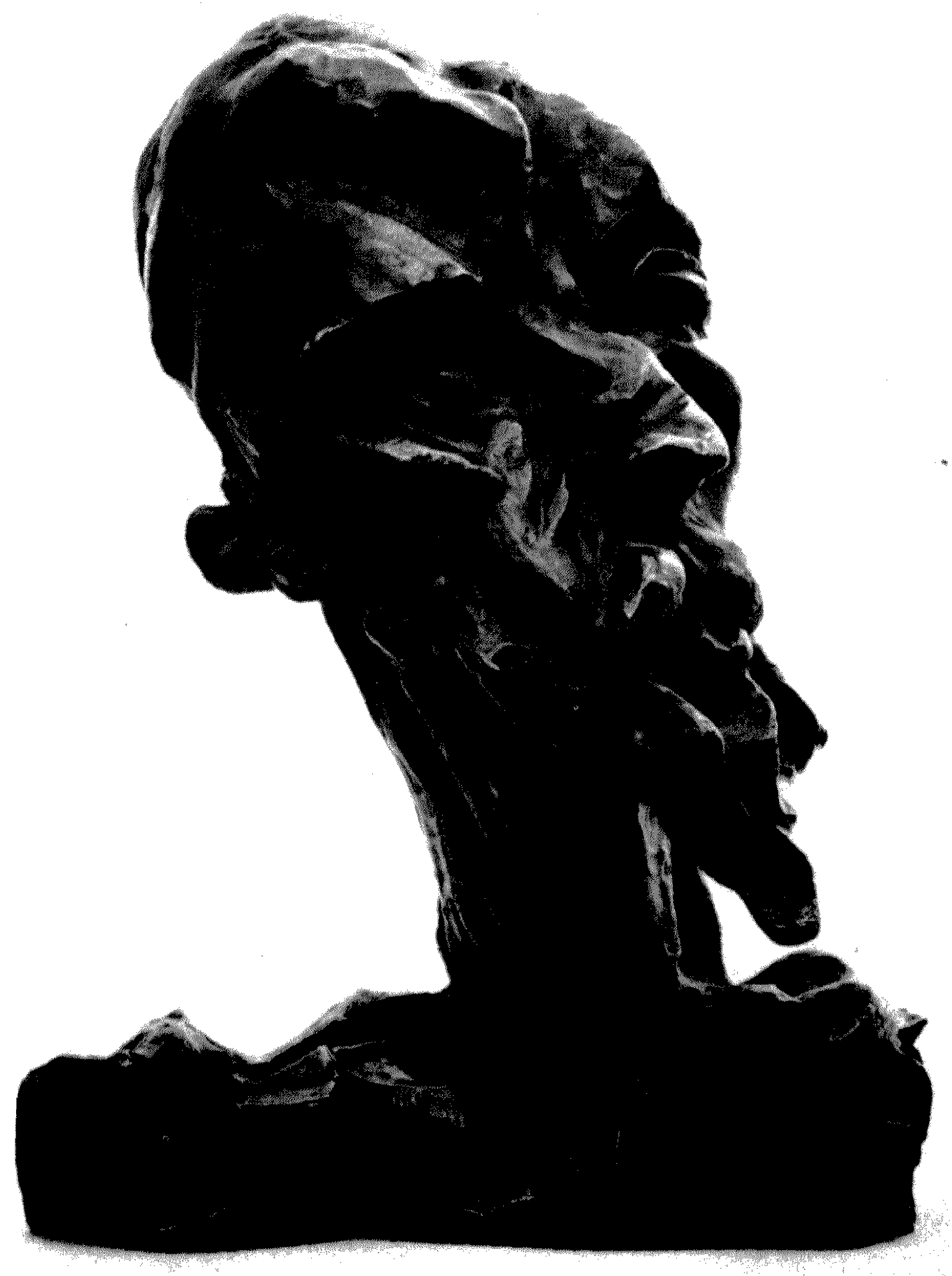

Ttro Gutfreund: "Don Quijoten (1912). Bronce.

(c) Consejo Superior de Investigaciones Cientificas Licencia Creative Commons

Reconocimiento 4.0 Internacional (CC BY 4.0) 


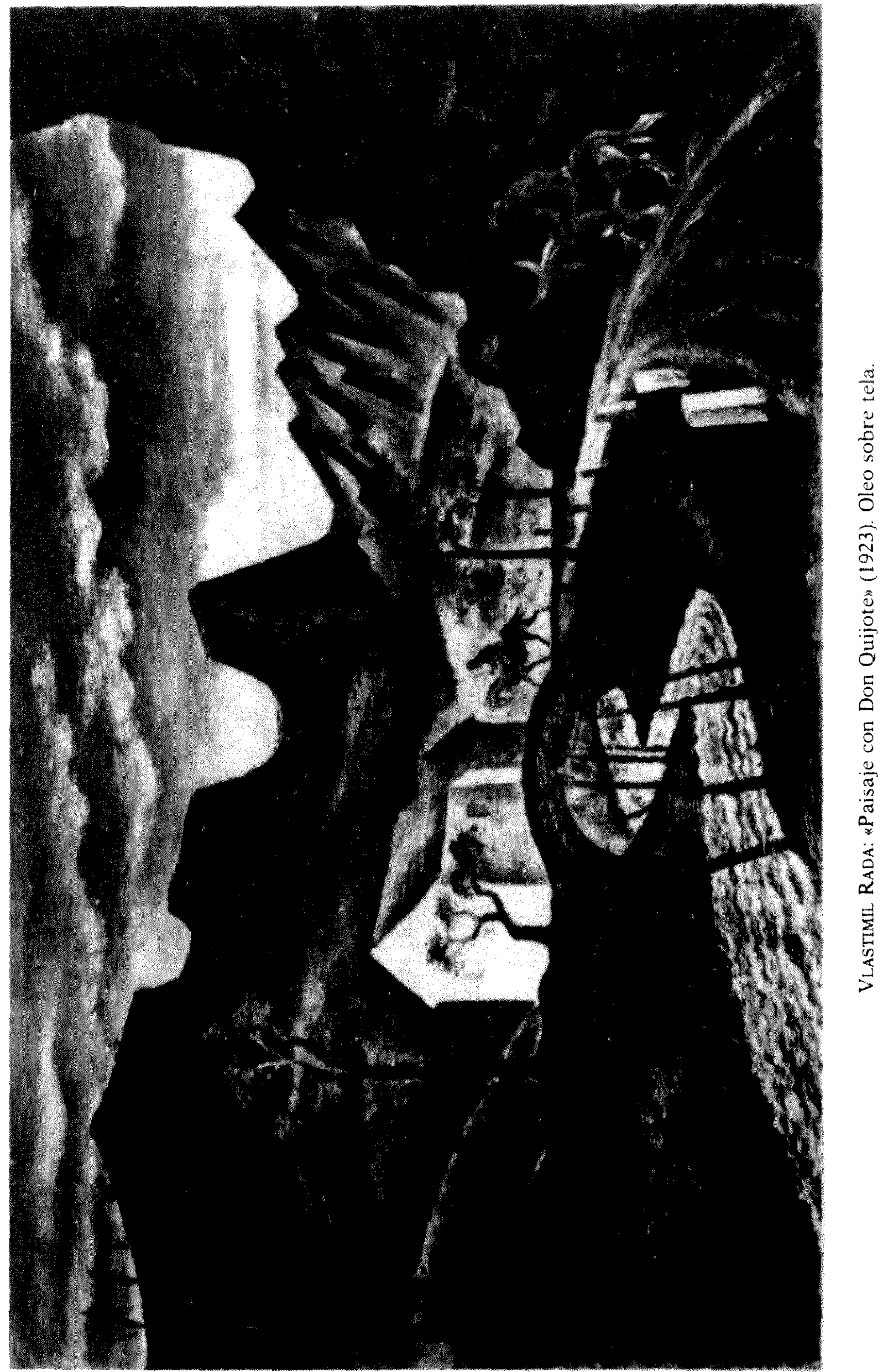

(c) Consejo Superior de Investigaciones Científicas 



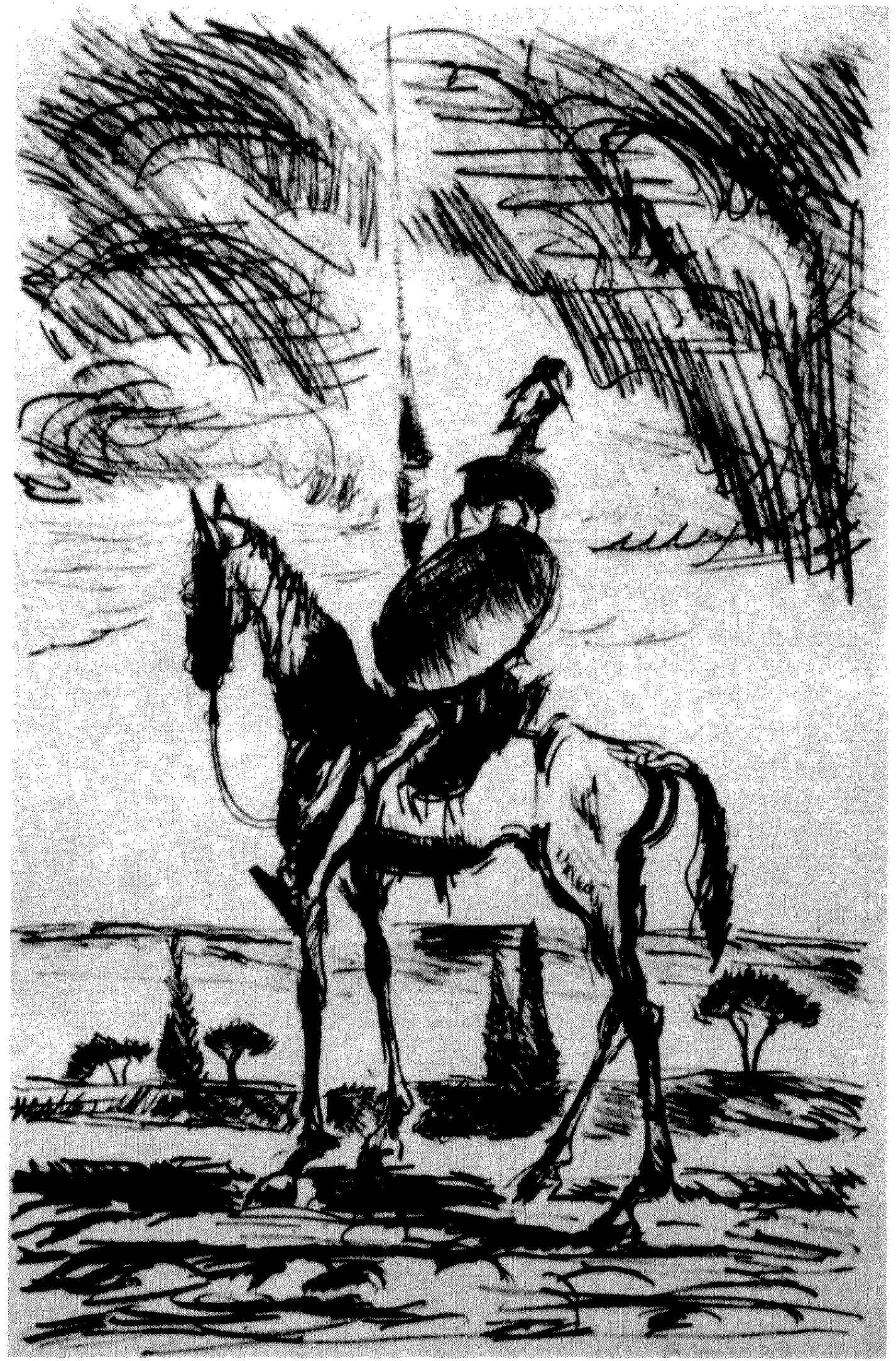

Cyprian MajerniIC: "Don Ouijote" (1944). Litografía. 


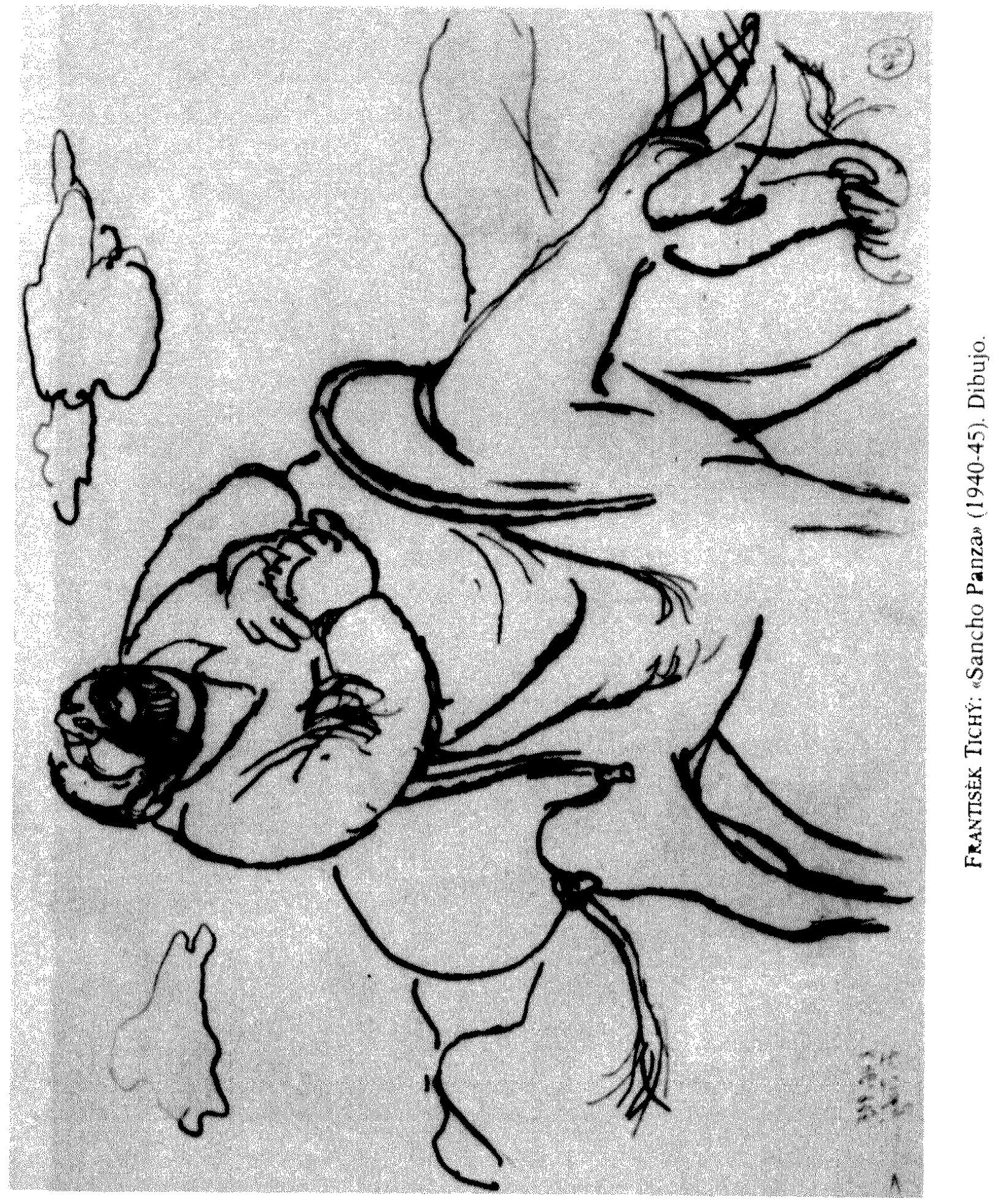




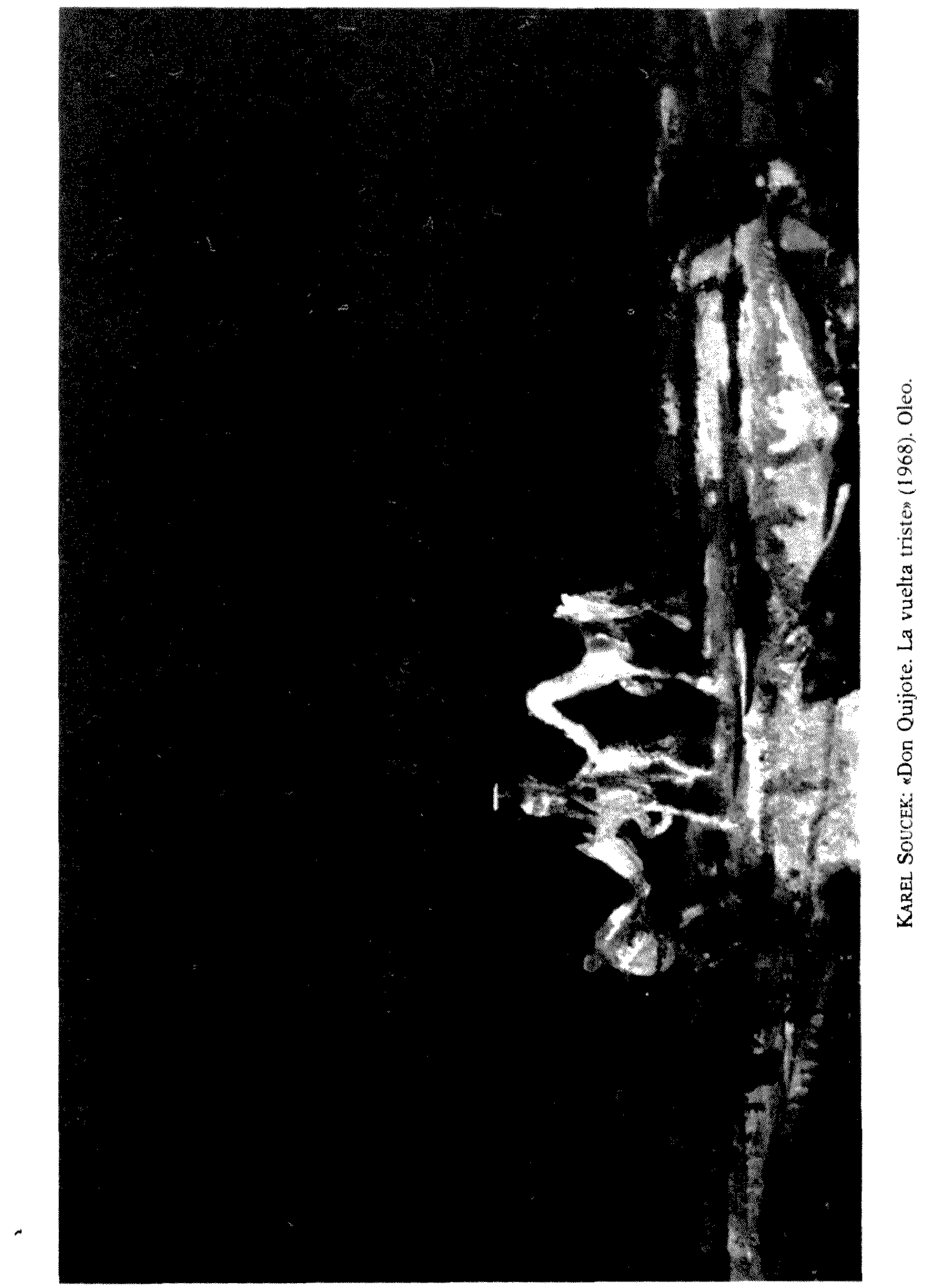

(c) Consejo Superior de Investigaciones Científicas 


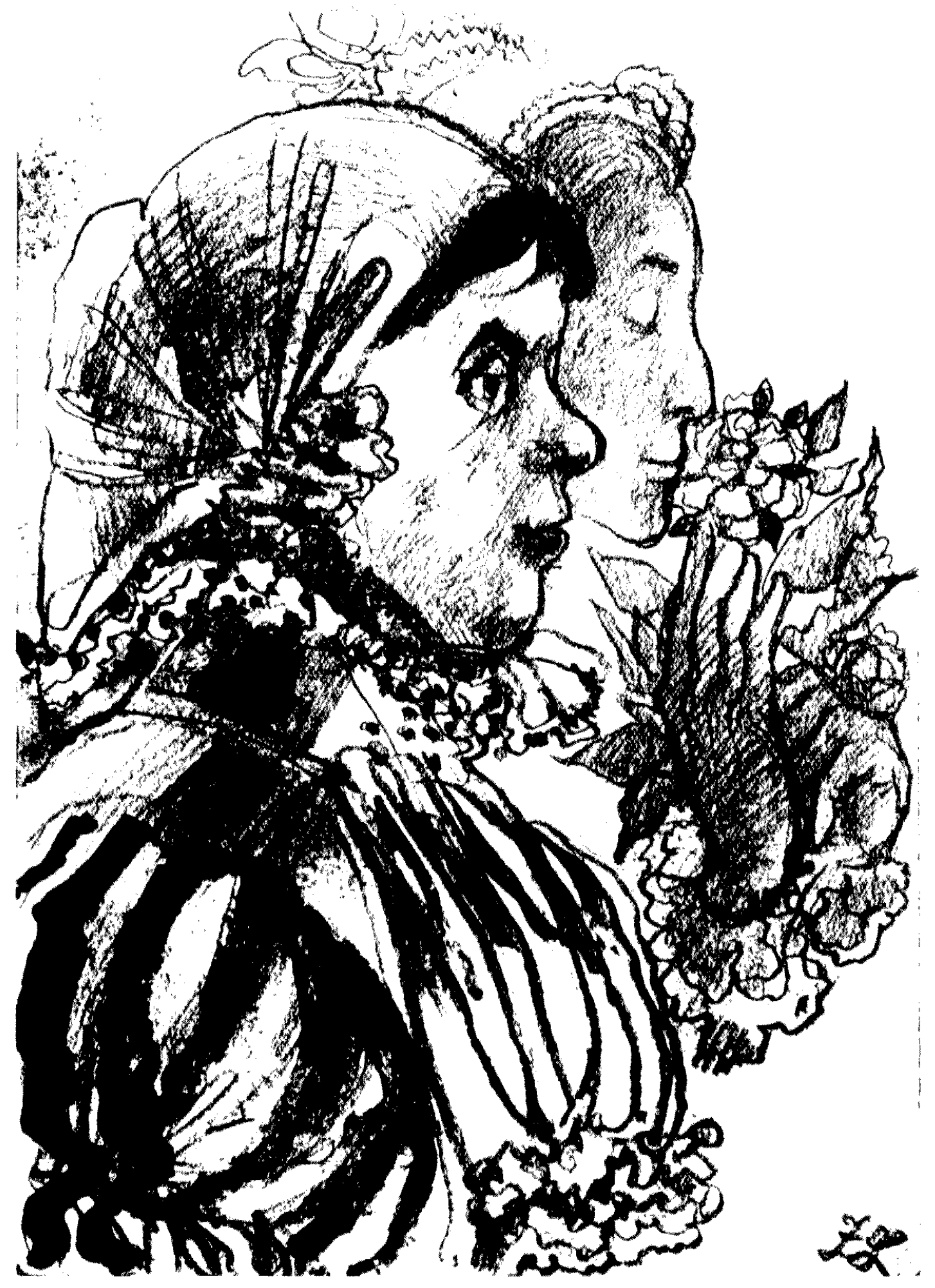

Zdeñka Landová: "Dulcinea del Tobos" (década de 1960). Dibujo con lápices a color. 


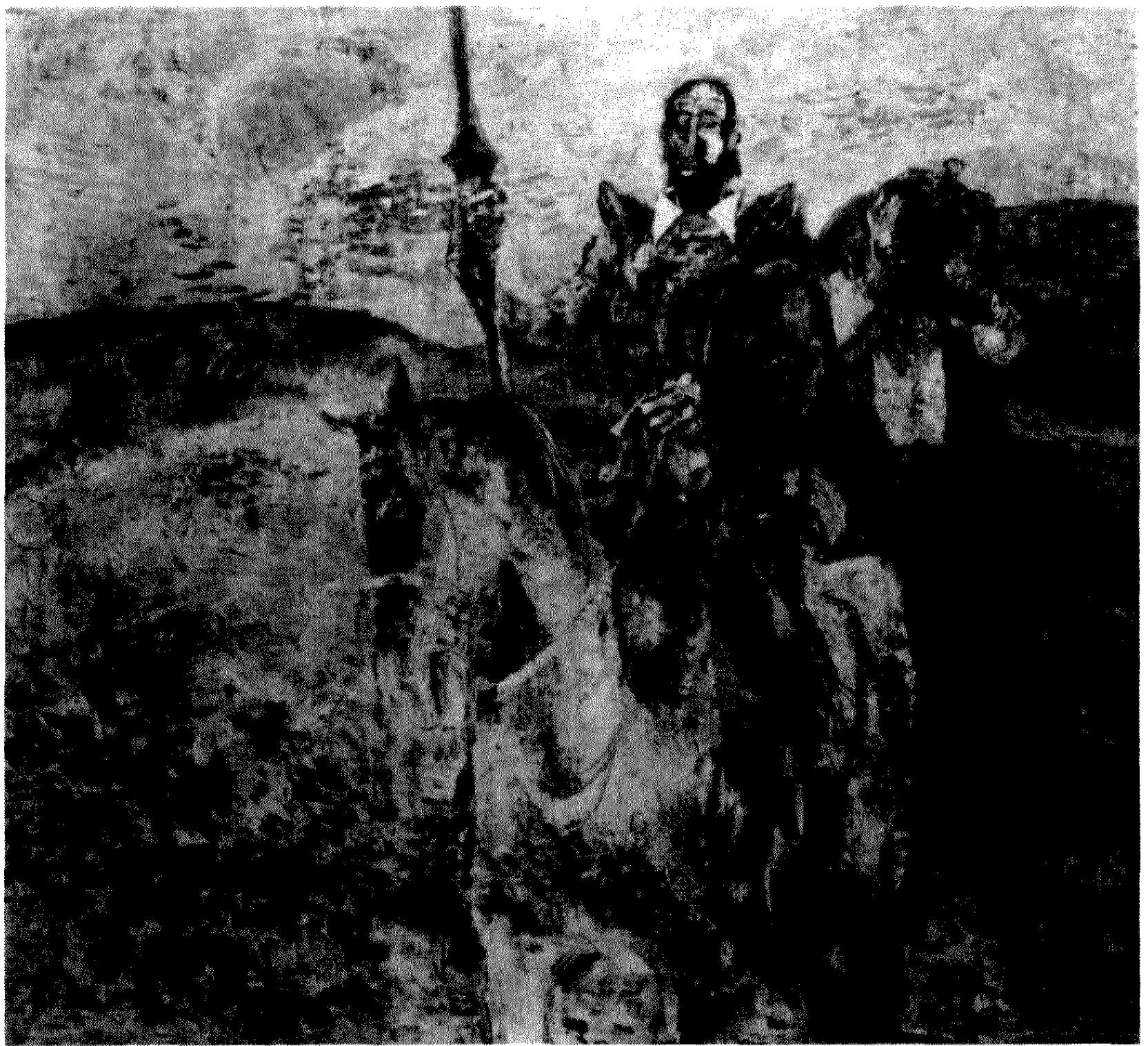

Ramomfr KoláR: «Don Quijote» (1971). Oleo sobre lienzo. 


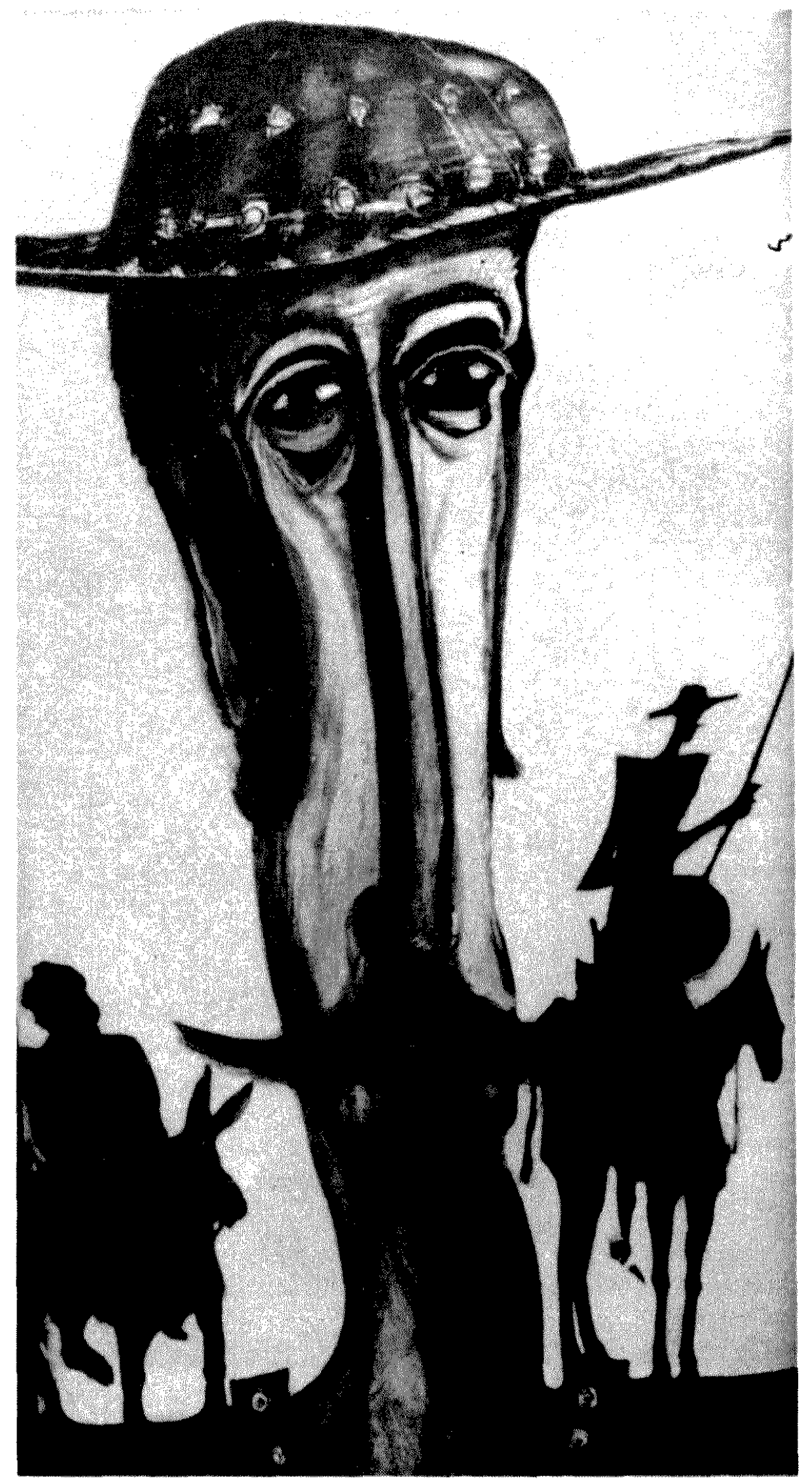

VÁClaV Frolík: "Don Quijoten (1986). Lienzo, acrilico.

(c) Consejo Superior de Investigaciones Científicas http://analescervantinos.revistas.csic.es Licencia Creative Commons

Reconocimiento 4.0 Internacional (CC BY 4.0) 


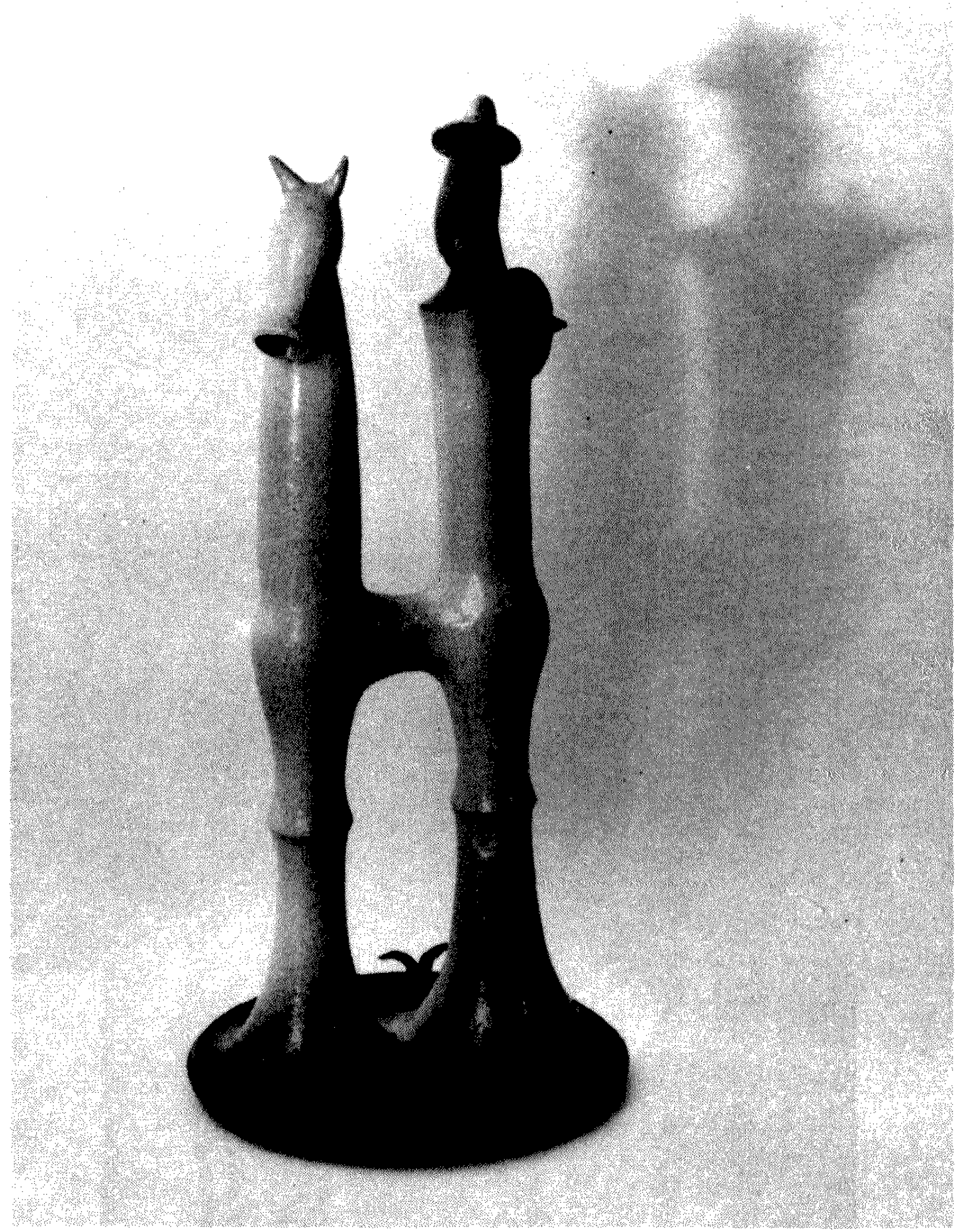

Gustav FifKa: „Don Quijote» (1988). Cerámica. 


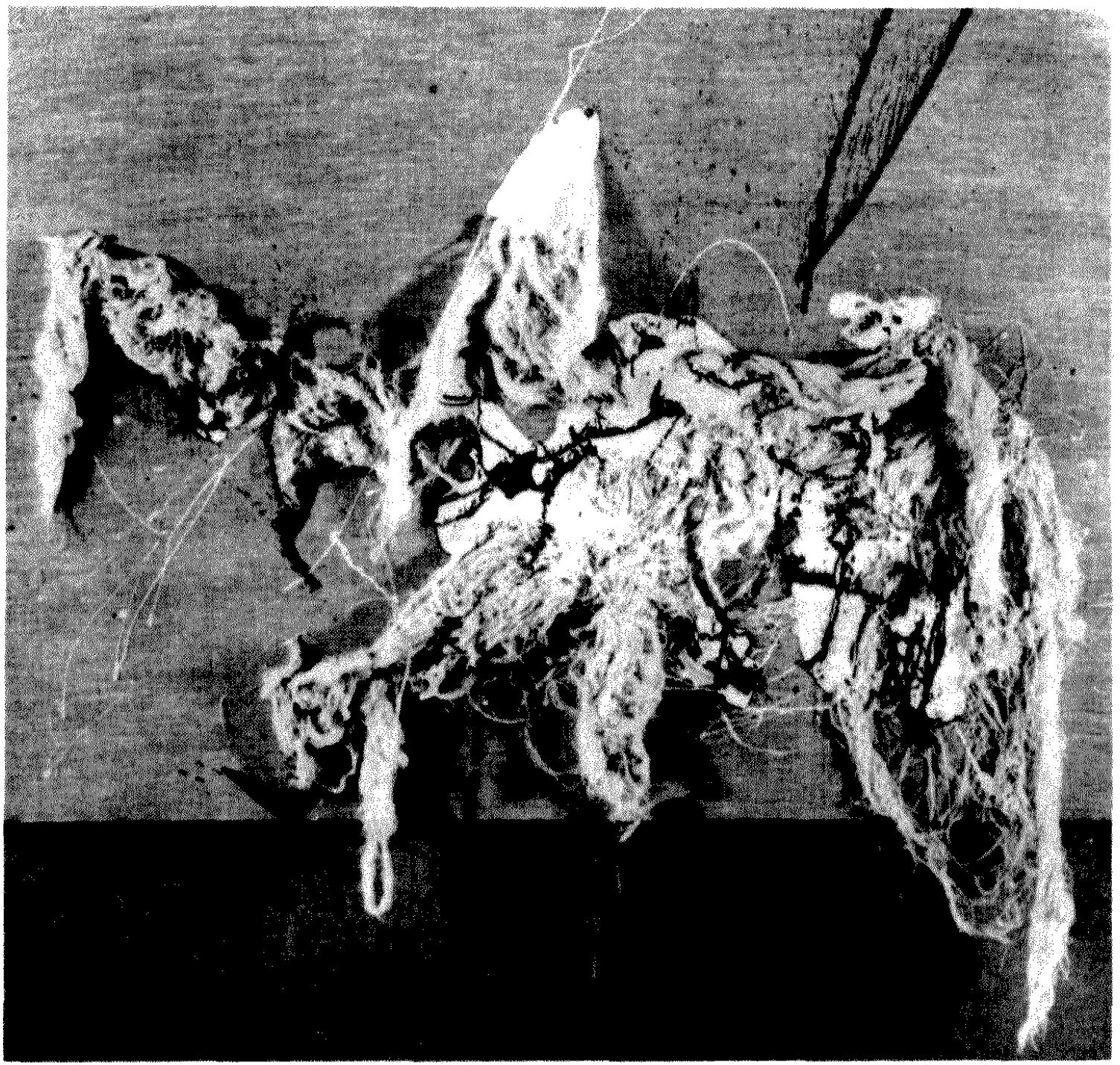

INE2 Tuschnerová: «Don Quijote» (1989). Técnica combinada. 